\title{
Sensory characterization of vegetarian pizza by using quantitative descriptive analysis
}

\author{
Ripudaman Singh, Kaushik Khamrui, Writdhama Prasad, Bhopal Singh and Ritika Puri
}

Received: 20 June 2020 / Accepted: 27 November 2020 / Published online: 07 June 2021

(c) Indian Dairy Association (India) 2021

\begin{abstract}
Consumption of vegetarian pizza is increasing worldwide for increasing popularity towards vegetarian diets. However, a proper description of sensorial attributes of vegetarian pizza is still not available in the existing scientific literature. Such characterization provides inevitable information for product's evaluation and process improvement. Therefore, the present study was undertaken to objectively characterize the sensory attributes of vegetarian pizza using statistical tools. A descriptive score card comprising all the possible sensory attributes of pizza was drafted and finalized by group discussion with sensory evaluation experts. Thirty six pizza samples were collected from different Indian cities. Sensory evaluation was done using Quantitative Descriptive Analysis (QDA) and significant $(\mathrm{p}<0.05)$ difference among the market samples was observed. Principal Component Analysis (PC) revealed five principal components (PC) which accounted for $93 \%$ variation in the sensory data viz., (1) cohesiveness of crust/cooking intensity/free moisture of cheese, (2) firmness/crispiness/type of crust, (3) cohesiveness/thickness of cheese, (4) chewiness, and (5) overall acceptability.
\end{abstract}

Keywords: Pizza, Principal Component Analysis (PCA), Sensory Evaluation, Quantitative Descriptive Analysis (QDA),

Dairy Technology Division, ICAR-National Dairy Research Institute, Karnal-132001 (Haryana), India

Writdhama Prasad ( $\square$ )

Dairy Technology Division, ICAR-National Dairy Research Institute, Karnal-132001 (Haryana), India

Ph: 0184-2259247; Fax: 0184-2250042; Email:

writdhama_3993@rediffmail.com,

\section{Introduction}

Pizza is world's most popular baked products and it can be defined as a plain bread leavened through chemicals or yeast (Redl et al. 2003), with pizza toppings consist primarily of tomato products and cheese, with ingredients such as, meat, onions, or peppers garnished on the top to provide variety. In pizza preparation, dough is formed into the shape of a pizza crust and thereafter dried in a convection or micro-wave oven. After the addition of pizza toppings, i.e., sauce and cheese and any additional ingredients, the whole mass is baked in a micro-wave or convection oven for predetermined time and temperature, the crust remains crisp throughout the baking process. On an average, this topping comprises about $45 \%$ of the weight of the finished pizza and rest $55 \%$ is the bread like crust. For the purpose of pizza topping, pasta filata variety of cheese is widely used across the world (Locci et al. 2008). The pizza market in India is worth above 1500 crores and is developing at a rate of $26 \%$ throughout the previous 5 years (Anonymous 2013). As indicated by Pizza Power (2013), a state of industry report, USA, Brazil, Russia, China and India are seen as developing pizza markets of the world. The sales of pizza have expanded from $\$ 28$ billion in 2000 to over $\$ 35$ billion in 2010 and it keeps on rising in USA (Nickle and Pehrsson 2013).

To produce a food product which could meet the expectations of consumer, it is very crucial to characterize the optimum sensory attributes of the particular product since it may prove to be a driving force for consumer acceptance and demand (Desai et al. 2013). Quantitative descriptive analysis (QDA) approach has been recognized as a tool for measurement and optimization of sensory attributes of various food products (Stone and Sidel 1998). The main principal of QDA is to impart adequate training to panelists who can measure the product attributes to obtain the quantitative description of that product which could be further analyzed statistically. In QDA approach, the key organoleptic attributes of the product are found out along with their appropriate intensity scales specific to that product. For this purpose, panelists work together in a focused group and by discussion among themselves they identify such attributes (Chapman et al. 2001). Terminologies defining the major sensorial attributes are generated by panelists, the 
resulting descriptions are important for profiling of sensory attributes and the analysis is efficiently utilized in modeling the predictions of consumer acceptability. Further, sensory evaluation sessions are conducted for panelists to identify and score product attributes. Results obtained by QDA can be analyzed statistically and then represented graphically.

PCA is a multivariate technique of extracting structure from a correlation matrix. The scores of various dependent variables obtained by descriptive analysis technique are subjected to further analysis in this technique to reduce the set of dependent variables (attributes) to a smaller set of underlying variables which are known as factors, based on the patterns of correlation among the original dependent variables (Lawless and Heymann 1998). PCA extract a new variable called a principal component for group of correlated original attributes. Further, second and third group are identified with derivation of factors for each, based on residual variance. PCA provides factor loadings which are represented as correlation of attributes with new dimensions and factor scores as values of products on new dimensions. Factor loadings are essential for interpretation of dimensions and the factor scores illustrate the relative positions among the products in a map (Jolliffe 2005). The results obtained by PCA has some fates such as profiling of specific product characteristic, comparing and contrasting similar products based on imperative attributes to consumers and thus increasing market share by making changes in product characteristics. Combination of QDA and PCA has been used to characterize sensorial attributes of many food products with great degree of success, such as ultra-pasteurized milk (Chapman et al. 2001), Cheddar cheese (Young et al. 2004), chocolate milk (Thompson et al. 2004), soy milk (Keast and Lau 2006), whey and soy proteins (Drake et al. 2007), fermented food products (Ghosh and Chattopadhyay 2012), labneh (Kaaki et al. 2012), yoghurt (Desai et al. 2013) and doda burfi (Chawla et al. 2014) and cham cham (an indigenous channa based dairy product) (Puri et al. 2016).

Owing to the fact that a major portion of Indian population is vegetarian, the consumption of vegetarian pizza is increasing and the trend is moving towards more and more appreciation of its sensorial attributes, as eating of pizza is becoming more common (De Vita et al. 2016). However a proper product description in terms of sensorial attributes of vegetarian pizza is still not available in the existing scientific literatures. Hence, the objective of this study was to identify lexicons with their definitions which could characterize the sensory attributes of vegetarian pizza using QDA and PCA. The information so obtained will be useful for understanding the most important sensory attributes of vegetarian pizza. Such information is crucial for optimizing the production process at commercial scale for preparation of vegetarian pizza having most desirable sensory attributes.

\section{Materials and Methods}

\section{Origin of the samples}

A total of thirty six samples of vegetarian pizza were collected from nine different prominent pizza manufacturer shops (four times from each shop) located in four cities of north India viz., Delhi, Chandigarh, Patiala and Karnal. As a few different varieties of vegetarian pizza were available, the most popular variety (Farm Fresh pizza) having similarity in style and types of toppings used was selected from each shop. The pizza toppings used in farm fresh pizza consisted primarily of mozzarella cheese, tomato sauce, onion, capsicum and tomato and black olive slices. Freshly prepared and packaged samples were procured from the individual shops and were packed in insulated containers (maintained at $30 \pm 1^{\circ} \mathrm{C}$ ). The packed samples were brought to the laboratory in about 3-4 hours time. Immediately after the samples were received, they were reheated to serving temperature $\left(50 \pm 2^{\circ} \mathrm{C}\right)$ by microwave oven $(100 \%$ power level for 2 minutes $)$ and presented for sensory evaluation to the trained sensory panelists.

\section{Experimental conditions of the sample}

Sensory evaluation was carried out in sensory evaluation laboratory of Dairy Technology Division. During the evaluation period, temperature of $24 \pm 2^{\circ} \mathrm{C}, 60-62 \%$ relative humidity and lightness intensity of 110 candle foot was maintained. For each evaluation, one quarter of a full pizza ( $50 \pm 2$ grams) of sample was presented at $50 \pm 2^{\circ} \mathrm{C}$ temperature to the panelists seated in individual booths. Each sample was served monadically with deionised water.

Ten trained sensory evaluation panelists, constituted from the faculty of Dairy Technology Division, National Dairy Research Institute, Karnal, India, developed the attribute terms for sensory evaluation of vegetarian pizza samples using QDA methodology (Chawla et al. 2014). The judges had previous experience in sensory evaluation of dairy products and were selected based upon their ability to detect the off-flavors in mozzarella cheese.

The ballot development for sensory evaluation was accomplished in six working sessions (each session of 1 hour). After the terminology development phase, the panelists were trained for the evaluation of pizza for a period of 2 months in 24 sessions of 1 hour each. The training consisted of evaluating surface characteristics of mozzarella cheese as described in Chel et al. (2009).

\section{Sensory analyses}

Factorial design was used for sensory evaluation of pizza samples, with sample*judge matrix in three different sessions. Each session comprised of three parts in which 7-8 sensory attributes were evaluated. The descriptive terms for each major 
sensory attribute category were developed by discussion, followed by consensus among the trained panel members. Similar approach has been reported by Puri et al. (2016) to generate sensory vocabulary. List of different descriptors (vocabulary) so finalized are provided in Table 1. Attributes were quantified with a linear intensity rating scale score card in which scale was from 0 to 10 ; where $0=$ attribute not detected and $10=$ attribute extremely strong (Chapman et al. 2001).

The main descriptors that were chosen to include in a score card used for sensory evaluation were six attributes for crust characteristics evaluation viz., firmness, crispness, cohesiveness, moisture absorption, pull-apart and type of crust. Two attributes for evaluation of topping characteristics viz., cooking intensity and amount of topping were used. For determining surface colour attributes, two attributes viz., blister colour and opaqueness; for surface consistency evaluation, the five descriptors free oil, free moisture, blister coverage, skinning and flow-off crust were used. For evaluation of melted cheese characteristics, three attributes viz., hardness, cohesiveness and chewiness were chosen. For evaluation of stretch characteristics three attributes viz., strand length, thickness and force to stretch were used.

\section{Statistical analyses}

The data were analyzed using IBM SPSS Statistics 20.0. Scores from ten panelists were used for descriptive statistical analysis. Analysis of variance (ANOVA) and Tukey test were employed for post hock multiple comparisons so as to analyze the descriptive data to determine whether the means were different significantly or not. PCA was applied to the means of all the attributes using factor analysis technique. The analysis extracted the most significant variables with minimum loss of information. A combination of Kaiser's criterion i.e., (eigen value $>1$ ) and the principal components that accounted for minimum $70 \%$ of the variance in the data set was applied to retain the number of final factors from the initial ones (Lawless and Heymann 1998). To facilitate interpretation of the results, the factors were orthogonally rotated (which leads to uncorrelated factors) by using the 'Varimax' method (Massart et al. 1988).

Table 1 Descriptors with definition used to explain the desirable quality parameters of Pizza

\begin{tabular}{|c|c|}
\hline Descriptors & Definition \\
\hline \multicolumn{2}{|l|}{ Crust Characteristics } \\
\hline Firmness & Force required to compress and cut the sample using incisors \\
\hline Crispness & The force by which the pizza sample shatter upon mastication \\
\hline Cohesiveness & Degree to which mass hold together due to inter particle bonding \\
\hline Moisture absorption & Amount of saliva absorbed by the pizza sample before swallowing \\
\hline Pull-apart & Force required to separate a bite size with teeth and fingers from rest of the specimen \\
\hline Type & Thinness or thickness of the crust. \\
\hline \multicolumn{2}{|c|}{ Topping Characteristics } \\
\hline Cooking intensity & Intensity of cooked flavor for cheese and vegetables \\
\hline Amount & Quantity of Cheese and vegetables on pizza \\
\hline \multicolumn{2}{|l|}{ Surface Colour } \\
\hline Blister colour & The intensity of the brown hue on the blisters. \\
\hline Opaqueness & The degree of opacity of the melted cheese. \\
\hline \multicolumn{2}{|l|}{ Surface Consistency } \\
\hline Free oil & The amount of free oil on surface of pizza. \\
\hline Free moisture & The amount of free moisture on the surface. \\
\hline Blister coverage & The amount of the surface covered by blisters. \\
\hline Skinning & Extent of layer formation on top surface of melted cheese. \\
\hline Flow-off crust & The quantity the cheese melted off the crust \\
\hline \multicolumn{2}{|l|}{ Melted Cheese Texture } \\
\hline \multicolumn{2}{|l|}{ Characteristics } \\
\hline Hardness & The force required to bite through the sample using molars. \\
\hline Cohesiveness & Degree to which the cheese tends to binds together during mastication. \\
\hline Chewiness & The total amount of energy required to masticate the sample to a state ready for swallowing. \\
\hline \multicolumn{2}{|l|}{ Stretch Characteristics } \\
\hline Strand length & How far the mozzarella cheese strand elongates before it breaks. \\
\hline Thickness & The width of the melted cheese strand. \\
\hline Force to stretch & The energy required to pull a strand. \\
\hline Overall Acceptability & The total sensory likeness and dislikeness of the product based on all the sensorial attributes tested. \\
\hline
\end{tabular}




\section{Results and Discussion}

\section{Descriptive analysis}

For sensory evaluation of samples, some specific terms were generated by discussing with the trained panel members, which were used as basic for QDA. After a consensus discussion among the panelists, list of different descriptors were finalized. Descriptive vocabulary generated by the panelists to describe the sensory attributes of pizza is presented in Table 1. Mean panelist ratings of overall quality of market samples of vegetarian pizza and attribute intensities for crust characteristics, surface colour, surface consistency, topping characteristics and melted cheese characteristics for samples of nine shops are listed in Table 2 .

\section{ANOVA and Post-hock test}

Analysis of variance was carried out on mean sensory scores of pizza samples collected from nine different shops (Table 2). All the studied attributes varied significantly $(\mathrm{p}<0.05)$ among the nine shops with the fact that some samples have overlapping qualities, however no such significant difference $(p<0.05)$ was obtained among the sensory results of panelists and for interaction effect between the panelist and shop. For the characteristic "firmness of crust", the sample P6 differed significantly $(\mathrm{p}<0.05)$ from P5, P8 and P9 samples. Firmness of the sample P6 was highly acceptable because it was neither too soft nor too hard so that it could be easily cut and compressed during mastication. Except samples P5, P8 and P9, all other samples did not differ significantly from P6. "Crispiness" of P6 sample was significantly $(\mathrm{p}<0.05)$ different from P2, P3, P4, P5, P7 and $\mathrm{P} 9$ and rest of the sample had similar crispiness as the sample P6. The difference in crispiness among samples was probably due to the excessive loss of moisture from the crust during baking. There was significant difference $(\mathrm{p}<0.05)$ in "cohesiveness of crust" among the samples P5, P6 and P9. Similarly, "moisture absorption" of P4 sample differed significantly $(\mathrm{p}<0.05)$ from P8 and P9. This variation in moisture absorption of pizza crust perceived by the sensory panelists may be due to the salivary flow difference of the individual panelists. de Delahaye et al (2005) reported differences in moisture absorption capacity of pizza for differences in their moisture content in crust. "Pull-apart" of sample P6 and P9 differed significantly $(\mathrm{P}<0.05)$ from all other samples. This may be due to the differences in textural characteristics of the pizza crust as well as difference in surface hardening that occurred at the bottom surface of crust during baking. "Type of crust" reflects the extent of thinness or thickness of the crust. Sample P6 obtained highest sensory scores because the thickness was found to be optimum by the judges and the score differed significantly $(\mathrm{P}<0.05)$ from all other samples. Crust thickness of sample P9 was highest and differed significantly $(\mathrm{P}<0.05)$ from sample $\mathrm{P} 1, \mathrm{P} 3, \mathrm{P} 6, \mathrm{P} 7$ and $\mathrm{P} 8$.
In topping characteristics, sample $\mathrm{P} 9$ was significantly different $(\mathrm{P}<0.05)$ from all other samples as it was highly baked and possessed intensely brown surface and sample P6 differed significantly in cooking intensity from P1, P3, P5 and P9. The reason for this difference could be the higher baking temperature $\left(280^{\circ} \mathrm{C}\right)$ or longer baking time $(6 \mathrm{~min})$ during pizza making. Sample P9 contained significantly $(\mathrm{P}<0.05)$ higher amount of pizza cheese and vegetables as compared to all other samples. The higher amount of pizza cheese and vegetables in sample P9 might be due to this particular shop added higher amounts of these ingredients to produce a better quality pizza than other rival shops.

Variation in surface colour of sample $\mathrm{P} 9$ varied significantly $(\mathrm{P}<0.5)$ from all other samples and the scores of this sample were higher as compared to other samples. It was probably because of the optimum baking of this sample. Blister colour of sample P9 was highly rated by the sensory panelists. Browning of blister to this extent was much liked by the judges. "Opaqueness" of sample P9 differed significantly $(\mathrm{P}<0.5)$ from sample P6. It was observed probably because in melted cheese, the temperature and amount of fat mainly influences the opacity and it differed due to fat content of the cheese varied. Opacity is temperature dependent and it reduces upon the cooking and cooling of cheese due to the fat coalescence which leads cheese to appear more translucent (Chen et al. 2009). Hence, probably the sample P7 and P9 either contained less fat and/or baked at higher intensity.

Surface consistency of samples differed significantly $(\mathrm{P}<0.5)$ for different shops. Presence of free oil on the surface of this sample was excessively high (more than 3 milliliters of oil from the surface of each sample presented to the panelist) which rendered it unfavorable to the judges. "Free moisture" of sample P9 varied significantly $(\mathrm{P}<0.05)$ from all other samples and sample $\mathrm{P} 5$ differ significantly from P6. "Blister coverage" greatly influences the consumer for purchasing pizza. Sample $\mathrm{P} 9$ was significantly $(\mathrm{P}<0.5)$ differed from all other samples in this attribute. "Skinning" of sample $\mathrm{P} 9$ was also significantly $(\mathrm{P}<0.5)$ different from all the samples. Skinning mainly depends upon the age of the cheese used, it's composition, oven type and baking conditions used. "Flow of crust" of the sample $\mathrm{P} 1$ differed significantly $(\mathrm{P}<0.5)$ from all the other samples. It might be due to higher amount of shredded cheese on the pizza base that would flow from the base to the outer sides during baking.

Melted cheese characteristics of sample P8 differ significantly $(\mathrm{P}<0.5)$ from $\mathrm{P} 1$ and the sample $\mathrm{P} 9$ varied significantly $(\mathrm{P}<0.5)$ from all other samples. Hardness of cheese is mainly due to the higher amount of protein content in cheese (Chen et al. 2009). "Cohesiveness of cheese" of sample P1, P4 and P7 differed significantly $(\mathrm{P}<0.5)$ from $\mathrm{P} 8$. It is the ability to hold cheese mass together after chewing. "Chewiness" of sample P1 was significantly $(\mathrm{P}<0.5)$ different from sample $\mathrm{P} 3, \mathrm{P} 4, \mathrm{P} 5, \mathrm{P} 6, \mathrm{P} 8$ and $\mathrm{P} 9$. Variation in cheese stretch characteristics of sample $\mathrm{P} 1$ differed significantly $(\mathrm{P}<0.05)$ from sample $\mathrm{P} 3, \mathrm{P} 4, \mathrm{P} 6, \mathrm{P} 7$ and $\mathrm{P} 8$. 


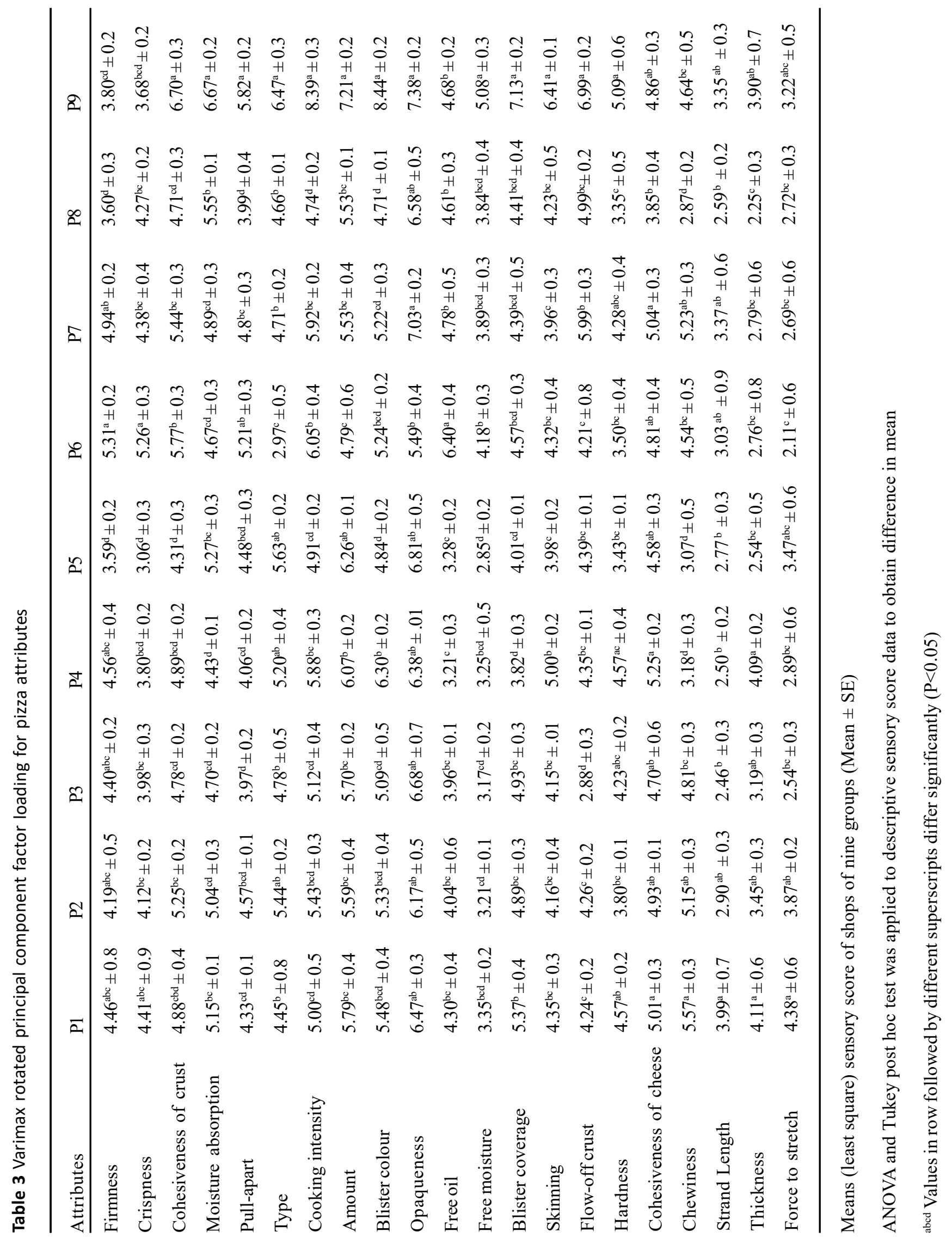


Fig. 1 Sensory profile of market samples of pizza from nine different pizza shops. Individual attributes are positioned like the spokes of a wheel around a center (zero, or not detected) point, with the spokes representing attributes intensity scales, with higher (more intense) values radiating outwards. (a) For crust and topping characteristics and surface colour; (b) for surface consistency, melted cheese texture characteristics, stretch characteristics and overall acceptability

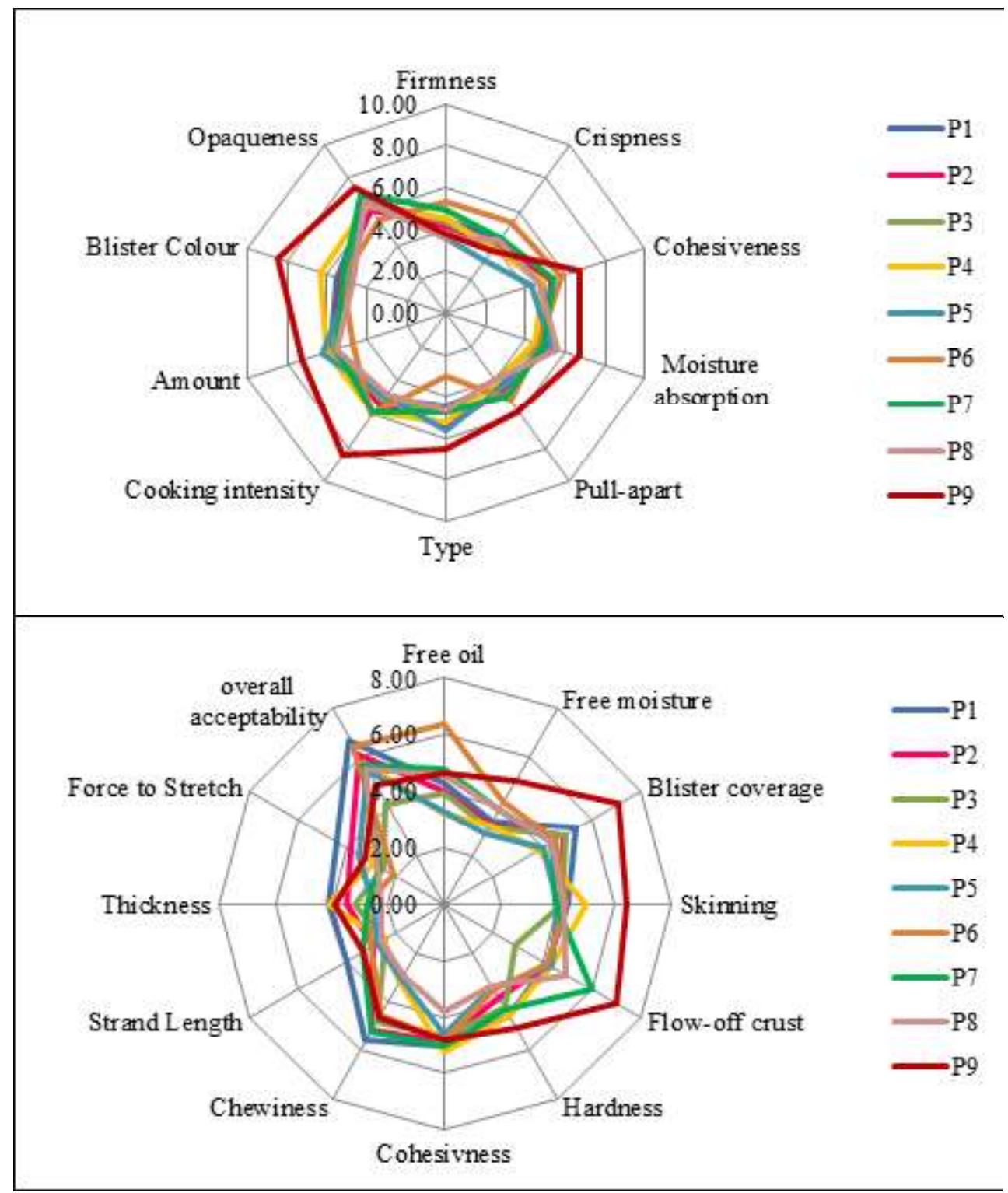

Spider plots were created by plotting average intensity scores on a corresponding scale and then joining the points (Stone and Sidel 1998). Fig $1 \mathrm{a}$ and $1 \mathrm{~b}$ shows attributes of the market samples of pizza from nine different pizza shops. This plot illustrates that "blister colour" and "cooking intensity" of sample P9 was maximum, which is not-desirable and lowest in P8 sample. It could also be seen that amount of cheese and vegetables was maximum in sample P9 followed by P5 and P4 and lowest in sample P6 and rest of the samples differed non-significantly. Crispiness was maximum of the sample P6 and lowest in sample P5 and other samples possessed no significant difference in this attribute. Crust type of sample P6 obtained minimum scores indicating it was a thinner sample and the sample P5 had thicker crust as compared to all other samples. It could also be observed that blister coverage of sample P9 was maximum and lowest in sample P5. Presence of free oil was maximum on sample P6 and lowest in P5.

\section{Principal Components Analysis (PCA)}

To eliminate descriptor redundancies and to simplify the data, PCA is used for transformation of original dependent variable into uncorrelated dimensions. PCA was applied to the mean attribute ratings listed in Table 2 to simplify the interpretation of data from 22 attributes measured on nine samples. To obtain specific knowledge about factors having critical importance among the sensorial descriptors, PCs were extracted based on maximum variance values. Among the PCs extracted, five PCs having eigen values $>1$ (Kaiser criterion) explaining $93.05 \%$ of the total variance in the data set were taken for further analysis. The results revealed that on the basis of eigenvector loadings, first PC with eigen value of 9.03 was able to explain $41.07 \%$ of the total variation whereas second $\mathrm{PC}$ with an eigen value 5.31 explained $24.14 \%$ of the variation and both the PC's (PC1 and 
Table 3 Varimax rotated principal component factor loading for pizza attributes

\begin{tabular}{|c|c|c|c|c|c|}
\hline Attributes & $\mathrm{PC1}$ & $\mathrm{PC} 2$ & PC3 & PC4 & PC5 \\
\hline Firmness & -0.026 & $-0.872 *$ & 0.407 & 0.146 & -0.087 \\
\hline Crispness & 0.143 & $-0.922 *$ & -0.081 & 0.203 & 0.091 \\
\hline Cohesiveness of crust & $0.923^{*}$ & -0.171 & 0.217 & 0.174 & -0.088 \\
\hline Moisture absorption & 0.732 & 0.568 & -0.281 & 0.183 & 0.102 \\
\hline Pull-apart & 0.879 & -0.119 & 0.066 & 0.168 & 0.078 \\
\hline Type & 0.239 & $0.912 *$ & 0.182 & -0.039 & -0.050 \\
\hline Cooking intensity & $0.911 *$ & 0.097 & 0.347 & -0.005 & -0.153 \\
\hline Amount & 0.415 & 0.861 & 0.264 & -0.018 & -0.045 \\
\hline Blister Colour & 0.797 & 0.332 & 0.487 & -0.032 & -0.055 \\
\hline Opaqueness & 0.294 & 0.776 & -0.013 & 0.269 & -0.269 \\
\hline Free oil & 0.518 & -0.765 & -0.305 & 0.210 & 0.008 \\
\hline Free moisture & $0.964 *$ & -0.137 & -0.083 & 0.092 & -0.109 \\
\hline Blister coverage & 0.734 & 0.287 & 0.138 & 0.485 & -0.036 \\
\hline Skinning & 0.809 & 0.340 & 0.377 & -0.142 & -0.062 \\
\hline Flow-off crust & 0.822 & 0.254 & -0.074 & 0.048 & 0.148 \\
\hline Hardness & 0.415 & 0.303 & 0.740 & 0.304 & -0.128 \\
\hline Cohesiveness of cheese & 0.035 & -0.160 & $0.915^{*}$ & 0.136 & 0.102 \\
\hline Chewiness & 0.117 & -0.284 & 0.354 & $0.856^{*}$ & 0.041 \\
\hline Strand Length & 0.331 & -0.076 & 0.178 & 0.683 & 0.552 \\
\hline Thickness & 0.160 & 0.204 & $0.882 *$ & 0.150 & 0.200 \\
\hline Force to Stretch & -0.177 & 0.519 & 0.228 & 0.387 & 0.683 \\
\hline overall acceptability & -0.079 & -0.480 & 0.069 & -0.010 & $0.863^{*}$ \\
\hline Variance explained $^{1}$ & $41.06 \%$ & $24.14 \%$ & $14.65 \%$ & $8.53 \%$ & $4.66 \%$ \\
\hline
\end{tabular}

Five PC were extracted by applying PCA on the mean values of descriptive sensory scores

*Number marked * are believed to be most important

${ }^{1}$ Refers to percent variance explained

Table 4 Factor score for market sample of pizza

\begin{tabular}{llllll}
\hline Attributes & $\begin{array}{l}\text { PC1 } \\
\text { Cohesiveness of } \\
\text { crust/ cooking } \\
\text { intensity/free } \\
\text { moisture }\end{array}$ & $\begin{array}{l}\text { PC2 } \\
\text { Firmness/ } \\
\text { crispness/type }\end{array}$ & $\begin{array}{l}\text { PC3 } \\
\text { Cohesiveness of } \\
\text { cheese/thickness }\end{array}$ & $\begin{array}{l}\text { PC4 } \\
\text { Chewiness }\end{array}$ & $\begin{array}{l}\text { PC5 } \\
\text { Overall } \\
\text { acceptability }\end{array}$ \\
\hline P1 & -0.50904 & 0.03169 & 0.61255 & 1.4601 & \\
P2 & -0.41749 & 0.07137 & 0.21155 & 0.26761 & 1.53707 \\
P3 & -0.99354 & 0.10602 & 0.19663 & 0.74424 & -2.1434 \\
P4 & -0.41089 & 0.09189 & 1.69587 & -1.81258 & -0.01943 \\
P5 & -0.74093 & 1.14554 & -0.77625 & -0.65089 & 0.45535 \\
P6 & 0.64693 & -2.26353 & -0.305 & -0.49351 & 0.12578 \\
P7 & 0.12101 & -0.51726 & -0.05251 & 0.89735 & -0.4364 \\
P8 & -0.02582 & 0.23087 & -1.9564 & -0.6532 & 0.07764 \\
P9 & 2.32977 & 1.10342 & 0.37356 & 0.24088 & -0.31882 \\
Variance & 41.061 & 24.147 & 14.650 & 8.531 & 4.658 \\
explained & & & & & \\
\hline
\end{tabular}

Factors scores were generated by applying PCA on descriptive sensory score data

${ }^{1}$ Refers to percent variance explained

PC2) explained $65.20 \%$ of the total variation. Third PC with eigen value of 3.22 was able to explain $14.65 \%$ variation, fourth PC having eigen value of 1.88 explained $8.53 \%$ variability and fifth PC with eigen value of 1.03 was able to explain $4.66 \%$ variability. For closer alignment with original variables, PCs were 
Fig. 2 Three-dimensional plot showing factors scores of market samples of pizza of Varimax rotated PC axes (a) PCI, PC2, PC3 and (b) PC3, PC4, PC5. Lables: Pizza shop codes (1-9)
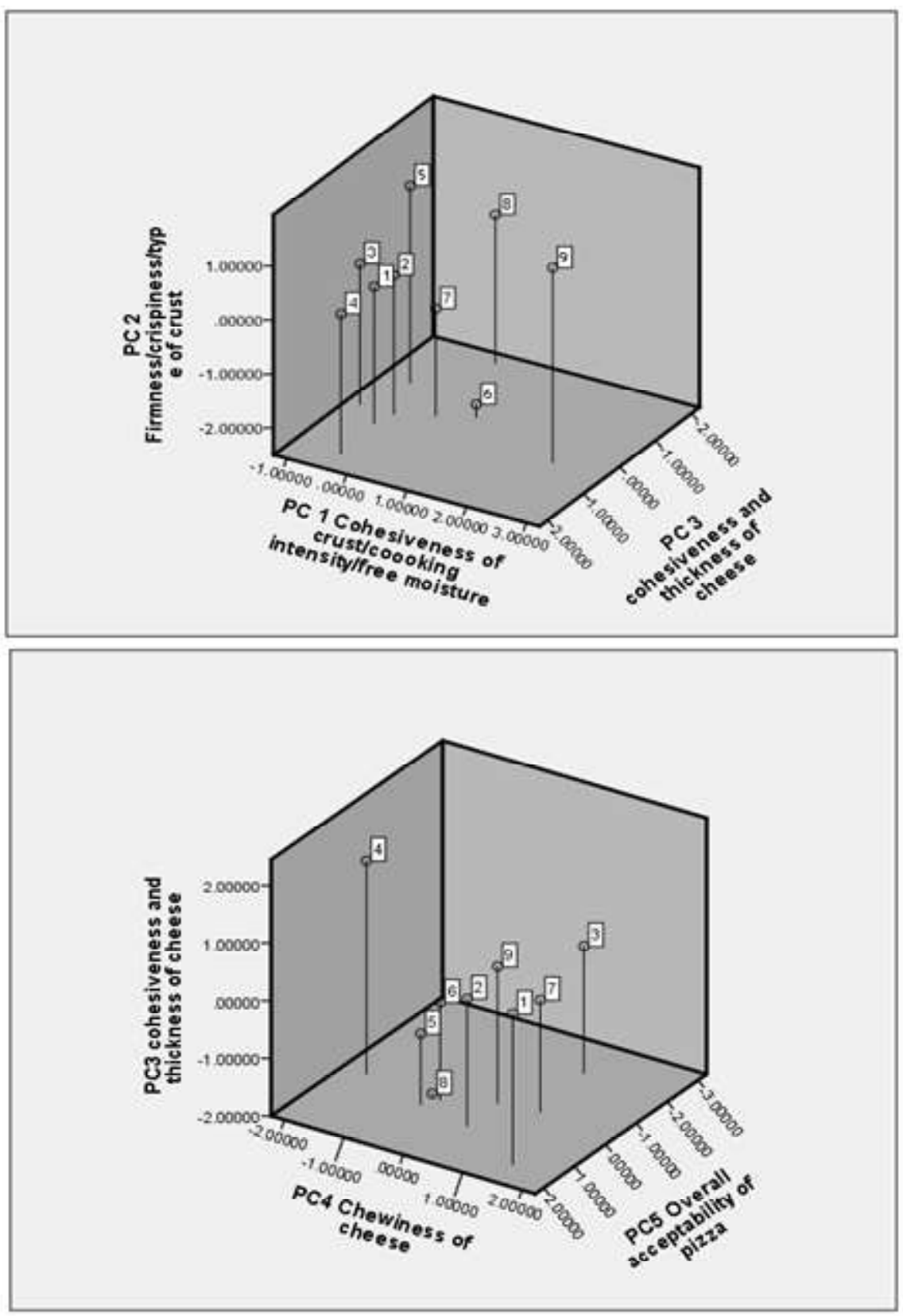

rotated using Varimax rotation method (Lawless and Heymann 1998). Rotation of variables resulted in factor loadings which represented correlation between PC and the original attribute. High factor loading values marked with asterisk were of chief importance. As shown in Table 3, absolute value of factor loadings corresponding to each sensory attribute decides the relation between principal component and that specific sensory attribute. PC1 was found to be entirely related to the "cohesiveness of crust", "cooking intensity" and "free moisture" as the loadings had maximum absolute values. More than one variable can be explained with the help of one principal component as suggested by Chapman et at. (2001). PC2 had large loadings for "firmness", "crispiness" and "type of crust".
PC3 was largely related to "cohesiveness of cheese" and "thickness of cheese strand" while PC4 was found to be influenced by "chewiness" and PC5 was found to be related to "overall acceptability".

For positioning or specifying the location of all the samples in three dimensional space, Varimax rotated PC factor score values (Table 4) can be utilized (Coxon 1982). Hence, with the help of three dimensional graphs the position of different samples of pizza along five PC generated were correlated (Fig. 2a and 2b). Products that were comparatively similar were found in close proximity to each other on the graph space, samples with significant difference were found far apart (Jolliefie 2005). It can 
be observed from Table 4 that sample group P6, P7 and P9 were shown to have positive factor score values from 0.121 to 2.330 for "cohesiveness of crust", "cooking intensity" and "free moisture" as compared to all other group samples as shown by negative factor score values from -0.026 to -0.994 , signifying that samples P6, P7 and P9 were not preferred by sensory panelists due to high surface moisture on cheese and more cohesive crust and also for higher cooking intensity of the sample P9. "Firmness", "crispiness" and "type" of P1, P2, P3, P4 and P8 groups was found more desirable as compared to P5, P6, P7 and P9 market samples P5 (1.146) and P9 (1.103) had higher score while P6 (2.264) and P7 (-0.517) had very low scores which could be observed by higher and smaller spike height on graph, respectively. At the same time scores for "cohesiveness of cheese" and "thickness" of samples from group P1 (0,613), P2 (0.212), P3 (0.197), P9 (0.374 and P4 (1.696) were found higher as compared to P5, P6, P7 and P8 groups as represented by taller spikes height shown in the Fig 2a. Factor scores for "chewiness" of sample P1, P2, P3, P7 and P9 were higher, sample P1 (1.460) and P7 (0.897) had highest factor scores among them as shown in Fig. 2b. Overall acceptability of sample P1 (1.537) had higher factor score and samples P2, P5, P6 and P8 also had higher positive factor scores as compared to sample P3, P4, P7 and P9 which were found to have negative factor scores signifying that samples from these groups were found undesirable to sensory panel members.

\section{Conclusion}

It could be concluded from the study that the sensorial attributes of vegetarian pizza samples could be properly defined using 21 descriptors and Principal Component Analysis identified nine prime descriptors (cohesiveness, cooking intensity, free moisture, firmness, crispness and type of crust, cohesiveness, thickness, chewiness) governed much of the variation of sensory attributes of vegetarian pizza. Hence, these attributes may be given prime importance while developing the product technology for industrial scale production.

\section{References}

Anonymous (2013) http://www.skymetweather.com/content/agricultureand-economy/october-is-national-pizza-month/ (accessed on $15 \mathrm{Feb}$ $\underline{2021)}$

Chapman KW, Lawless HT, Boor KJ (2001) Quantitative descriptive analysis and principal component analysis for sensory characterization of ultrapasteurized milk. J Dairy Sci 84:12-20

Chawla R, Patil GR, Singh AK (2014) Sensory characterization of doda burfi (Indian milk cake) using Principal Component Analysis. J Food Sci Technol 51: 558-564

Chen C, Wolle D, Sommer D (2009) Mozzarella. In: Clark S, Costello M, Drake MA, Bodyfelt F ( $2^{\text {nd }}$ ed) The Sensory Evaluation of Dairy Products, New York, NY: Springer, 459-487

Coxon APM (1982) Three-way and further extensions of the basic model. The Users Guide to Multidimensional Scaling. Heinemann Educational Books, London. 186-241
Desai NT, Shepard L, Drake MA (2013) Sensory properties and drivers of liking for Greek yogurts. J Dairy Sci 96:7454-7466

Drake MA, Jones VS, Russell T, Harding R, Gerard PD (2007) Comparison of lexicons for descriptive analysis of whey and soy proteins in New Zealand and the USA. J Sens Stud 22:433-452

Di Vita G, De Salvo G, Bracco S, Gulisano G, D’Amico M (2016) Future Market of Pizza: Which Attributes Do They Matter. AGRIS Papers Econo Infor 8: 59-71

de Delahaye EP, Jimenez P, Perez E (2005). Effect of enrichment with high content dietary fiber stabilized rice bran flour on chemical and functional properties of storage frozen pizzas. J Food Eng 68:1-7

Ghosh D, Chattopadhyay P (2012) Application of principal component analysis (PCA) as a sensory assessment tool for fermented food products. J Food Sci Technol 49:328-334.

Jolliffe I (2005) In: Principal component analysis. John Wiley \& Sons Ltd, 78-110

Kaaki D, Baghdadi OK, Najm NE, Olabi A (2012) Preference mapping of commercial Lebneh (strained yoghurt) products in the Lebanese market. J Dairy Sci 95:521-532

Keast RSJ, Lau JJ (2006) Culture-Specific Variation in the Flavour profile of Soymilk. J Food Sci 71:S567-S572

Lawless HT, Heymann H (1998) In: Sensory Evaluation of Food: Principles and Practices. Chapman \& Hall, New York, NY, pp. 585-608

Locci F, Ghiglietti R, Francolino S, Iezzi R, Oliviero V, Garofalo A, Mucchetti G (2008) Detection of cow milk in cooked buffalo Mozzarella used as Pizza topping. Food Chem 107:1337-1341

Massart DL, Vandeginste BGM, Deming SN, Michotte YKAUFMAN, Kaufman L (1988) Principal components and factor analysis. In: Chemometrics: A Textbook. Elsevier, Amsterdam, 339-369

Murray JM, Delhunty CM, Baxter IA (2001) Descriptive sensory analysis: past present and future. Food Res Int 34: 461-471

Pizzolongo F, Quarto M, Nasi A, Ferranti P, Addeo F, Sacchi R, Chianese L (2007) Sensory profile of PDO Mozzarella di Bufala Campana Cheese. Ital J Animal Sci 6: 1136-1139

Puri R, Khamrui K, Khetra Y, Malhotra R, Devraja HC (2016) Quantitative descriptive analysis and principal component analysis for sensory characterization of Indian milk product cham-cham. J Food Sci Technol 53:1238-1246

Redl A, Guilbert S, Morel MH (2003) Heat and shear mediated polymerization of plasticized wheat gluten protein upon mixing. J Cereal Sci 38: 105-114

Stone H, Sidel JL (1998) Quantitative descriptive analysis: developments, applications and the future. Food Technol 52: 48-52

Thompson JL, Drake MA, Lopetcharat K, Yates MD (2004) Preference mapping of commercial chocolate milks. J Food Sci 69: 406-413

Young ND, Drake M, Lopetcharat K, McDaniel MR (2004) Preference mapping of Cheddar cheese with varying maturity levels. J Dairy Sci 87: $11-19$ 